\title{
ANALYSIS OF THE MORBIDITY WITH TEMPORARY INCAPACITY FOR WORK AMONG WORKERS AT THE SHIPBUILDING AND SHIPREPAIRING COMPANY
}

\author{
Dimitrova T. ${ }^{1}$, I. Zlatarov $^{2}$, E. Tsankova ${ }^{3}$, D. Demireva $^{4}$ \\ ${ }^{1}$ Department of Medico-biological sciences, MU-Varna, ${ }^{2}$ Department of Hygiene and Disaster \\ Medicine, MU Varna, ${ }^{3}$ Medical College, Varna, ${ }^{4}$ Regional inspection for public \\ health protecting and control
}

\section{Reviewed by: Assoc. Prof. St. Popova}

\begin{abstract}
Aim: To analyse the yearly morbidity with temporary incapacity among workers at the shipbuilding and ship-repairing company as compared to norm groups after Batkis-Lekarev, previously defined values according to groups of disease - standard and registered illnesses of the population aged 18 and above in general hospitals in Varna district for the period 2004-2006. The comparative analysis for the period 2004-2006 shows that the negative tendencies in the morbidity with temporary incapacity for work have decreased during the past year. The structure of morbidity shows that the basic reasons for temporary incapacity for work of the working team as a whole are mainly diseases of the respiratory, musculo-skeletal system and diseases of the peripheral nervous system, which can be explained with the specific type of work. Special attention should be paid to the fact that the frequency of absences from work because of malignant growths grows double each following year. The progression of the sickness related to the peripheral nervous system, neuroses and eye diseases is similar. The presence of some of these diseases could be related directly with the working conditions.
\end{abstract}

Key words: morbidity, temporary incapacity, shipbuilding, shiprepairing

The data from the morbidity with temporary incapacity for work (MTIW) reflect the morbidity rate among active people, at an age that makes them able to work and so they are of general medical interest, tackling work, social, medical and clinical problems. Health statistics is the basis of the monitoring of the health condition of the employees and constitutes an element of the assessment of risk. Promotion of health at the workplace with an emphasis on the topical problems according to the analysis of the state of health is a priority of the contemporary concept for company policy for health and safety.

\section{AIM}

To analyse the yearly morbidity with temporary incapacity among workers at the shipbuilding and ship-repairing company as compared to norm groups after Batkis-Lekarev, previously defined values according to groups of disease standard and registered illnesses of the population aged 18 and above in general hospitals in Varna district for the period 2004-2006.

\section{Address for correspondence:}

T. Dimitrova, Dept. of Medico-biological sciences, Medical University of Varna, 55 Marin Drinov str., BG-9002, Varna

e-mail:tvd@mnet.bg

\section{MATERIALS AND METHODS}

The object of the research during 2006 were 713 people, of whom 662 or $92.85 \%$ were men, and 51 or $7.15 \%$ were women. In 2005 the list of the average number of workers was 601 people, of whom men were 555 or $92.35 \%$, and women were 46 or $7.65 \%$. The average number of workers on the staff list of the company in 2004 was 597 people, 565 or $94.64 \%$ men and 32 or $5.36 \%$ women.

The analysis of sick rate was done on the basis of a comparative analysis of the level of morbidity per annum for 2004, 2005 and 2006. All patients' charts have been analysed 784 altogether, issued during the period of observation and the data were processed according to the confirmed indicators of frequency, seriousness of disease and average length of one case with temporary incapacity for work. An additional analysis has been carried out for establishing the connections between the level and structure of a disease in relation to age, sex and profession. The International classification of a disease has been used for analysis of the most frequent illnesses in relation to the location of the disease. On a comparative analysis of the spread of nosologic units partial incompatibilities with the encoding of the diseases have been encountered and they are connected with the period from $9^{\text {th }}$ to $10^{\text {th }}$ revision of the International Classification of Diseases which has been officially accepted in the Republic of Bulgaria with the changes of the Health Law enforced on 1st of January, 2005. 


\section{RESULTS}

During 2004, 1,062 cases of absence from work have been registered because of temporary incapacity for work, for which 9,627 work days were lost, while during 2005 the cases were 1,360 and 11,668 days were lost. In 2006 the number of cases - 1,362 and lost days - 12,489 were nearly the same.

Part of the cases and days were because of nursing a sick person from the family or a maternity leave respectively in 2004, 22 cases and 283 days during 2005, 20 cases and 120 days, while during 2006, 14 cases and 89 days. In the ensuing data analysis, these cases and lost days have been excluded since they have no relation with the conditions of work with the company.

On average 1 person with temporary incapacity for work correlates with 2.04 cases, and with women this indicator is respectively 1.65 , while with men -2.06 cases (2004). The following year (2005) these indicators get worse and 1 person correlates with 2.19 cases, with women -2.00 , while with men -2.20 cases. In 2006 we observe the least number of cases per person - 1.91 and each woman correlates with 1.62 cases on average, while with men - 1.92 cases.

A tendency has been observed for decreasing the frequency of using sick leave by workers and administrative staff from the company during the last year of report. The least number of sick leaves used by women was registered in 2006 . On average 1 person who used a sick leave during 2004 correlates with 23.13 lost days, while with men this indicator is 23.3 days, and with women - 20.30 days (2004). This shows again that men have been on sick leave for a longer period of time. During the following year (2005) the average period tends to grow - 23.61 days as a whole, and with men - 23.56 days, while with women - 25.1 days. During the last period analysed (2006), the length of MTIW suddenly drops to 22.67 days on the whole, and with men - 22.72days, while with women - 21.46 days.

The average age of the people who have used a sick leave increases with every other year - in 2004 it is $37.33 \pm 0.69$., in $2005-37.53 \pm 0.32$, while in 2006-38.42 \pm 0.33 .

When it comes to distribution according to the age in 2004 the greatest number of cases with men is between the ages 20-29 years old (32.4\%), while the lost days away from work were most with the next age group of people 40-49 (28.5\%). Women tend to lose days at work again at the same age group 40-49, while the most frequently sick people were at the age of 30 to $39-31.6 \%$ of all the diseases from representatives of this sex. Men have a similar spread of age groups both in 2005 and 2006. Nearly half of the lost days $(41.7 \%)$ were by women at the age of 50-59 while in this age group the highest relative share of both the cases $(30.8 \%)$ and the people, who used a sick leave, are (29.2\%). During the whole analysed period the ship builders were the ones with the highest relative share of all people who had a sick leave. In 2006 every fourth case of MTIW was with a ship builder (27.7\% of all cases of MTIW) and a quarter of the days lost because of temporary incapacity for work belongs to ship builders ( $25.6 \%$ of all days). While ranging them according to professional groups that have been affected, fitters and shipyard welders constitute $18.4 \%$ and $17.1 \%$ respectively of all the cases. These relative shares remain almost the same during the three periods analysed. The structure of cases in relation to different disease categories according to the international classification of diseases shows that during 2004 - the most common happen to be the diseases of the respiratory system $42.1 \%$ of the cases with women and $44.9 \%$ with men. With women the cases of diseases of the digestive tract come second $15.8 \%$, while with men next come diseases that affect the musculo-skeletal system $13.2 \%$.

The spread of temporary incapacity for work according to disease categories in 2005 with both sexes and as a whole shows a tendency for concentration of the cases on the respiratory system. Relatively nearly half of all patients' charts and one fourth of the absences from work with men and as a whole were due to pulmonary pathology. With women the first place according to the relative share of days away from work are due to injuries of the bone and muscle system. Both for women and men the percentage of the days away from work due to some kind of trauma is respectively $22.3 \%$ and $23.0 \%$.

As a whole and with women the lost days away from work again are because of respiratory diseases which come first with $24.9 \%$ and $31 \%$, but with men most days away from work are due to traumas $25.2 \%$.

While in 2004 and 2005 the distribution according to the nosologic unit of diseases was relatively uneven, in 2006 we observe a common distribution of the temporary incapacity for work according to different disease categories when it comes to both cases, as well as lost days. Again the pathology of the respiratory system comes first, followed by diseases of the bone and muscle system and traumatism. In 2004, 11 cases of accidents at the workplace have been registered, in 2005 - 15, and in 2006 the number of accidents was 17 with days away from work 808, 858 and 610 days respectively.

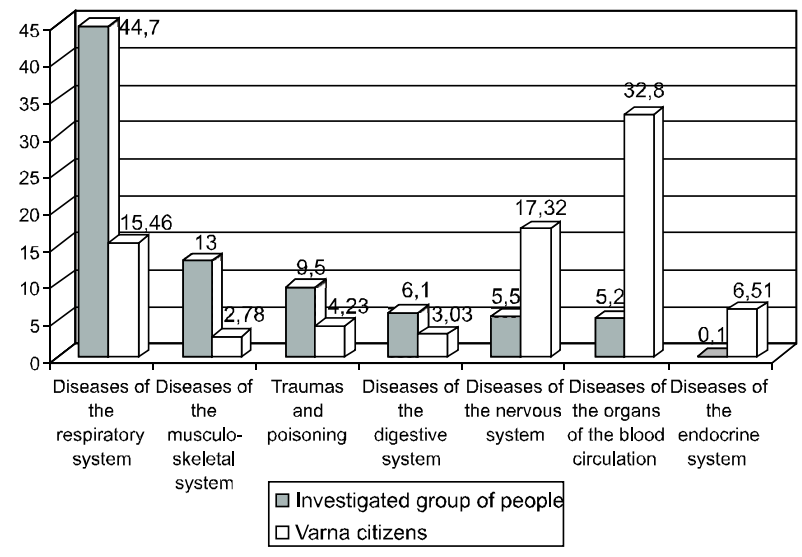

Fig. 1. Distribution of the most frequent nosologic units among cases of MTIW (MORBIDITY WITH TEMPORARY INCAPACITY FOR WORK) and the morbidity rate of the adult population from Varna district in 2004 (relative share \%) 
According to the morbidity of the people over 18 years of age in Varna district what impresses us most is the high incidence of diseases of the respiratory system among the workers of the staff. Among the rest of the people from the region during the three years of analyses the morbidity connected with cardiovascular diseases comes first. This allows us to connect the respiratory pathology mainly with factors of the work environment. The pulmonologic finding has been related to the exposure to dust and toxic substances, part of which - irritating gases in the process of welding, disturb the distal bronchioles and epithelial cells Clara with anti-inflammatory and immunosuppressive secretory function. The data from different research among workers in ship repairing yards happen to be similar $(2,3,4)$. In 2004 and 2005 second place in the relative share of MTIW cases in the investigated shipbuilding company are the illnesses related to the musculo-skeletal system. They constitute a higher percentage in relation to the relative share among the adult population of the region. Other authors also report a higher frequency of this nosologic unit among workers in shipbuilding and metal processing. This fact is mainly related to the enforced work posture and the manual labour, which are widely used in the work environment of this branch of industry.

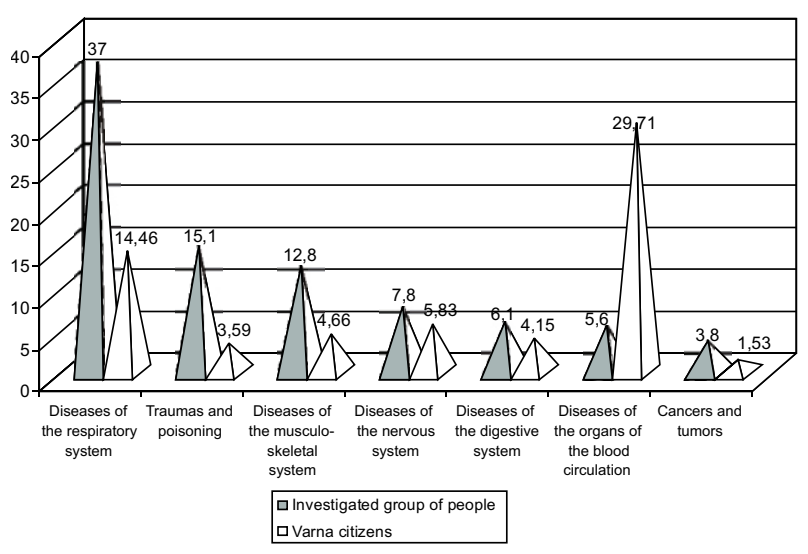

Fig. 2. Distribution of the most frequent nosologic units among the cases of MTIW

The relative share of the MTIW is also high due to traumas in relation to the population.

We are impressed by the low morbidity from diseases of the endocrine system in relation to the one of the population of the region. Most probably this fact is due to the way these diseases develop and the rare cases of necessity for being absent from work because of illness due to diabetes and the rest of the endocrine diseases.

The frequency of cases and the frequency of the days of temporary incapacity for work in relation to a malignant pathology (mainly localized in the organs of the respiratory and digestive system) demonstrate a growing tendency. We establish an excessive frequency of the days in 2006 of previously defined values according to disease group - standards. The malignant growths of the workers in this branch of industry are associated with the wide-spread harmful habits of the workers in the team and their exposure to as- bestos. Investigations carried out among ship builders and crews engaged in repairing vessels show data for the risk of cancerogenic exposure $(5,6,7,8,9)$.

The relative share of both cases and MTIW days because of psychological and behavioural disturbances during the last year analysed have increased threefold. Neuroses and psychiatric diagnoses predominate among the administration in relation to the people engaged in shipbuilding.

These illnesses and especially the depression, similar to other authors, we connect mainly with the neuro-psychological stress at the workplace and its influence combined with social tension in the family (1).

Frequency (more than 3 cases per year) and duration (more than 30 days) with sick administrative staff and workers have an important significance for the formation of the indicators for the general morbidity. These 118 people, who constitute $19.76 \%$ of the average list of staff in the company, form 6,492 or $69.48 \%$ of the lost days in the company in 2004. During the last period of analysis, a tendency has been established for decreasing the relative share of the people who are frequently sick or are sick for a long time 155 or $21.74 \%$, but the lost days by these people increase up to 8,846 or $71.43 \%$.

In 2006 in comparison with the previous years in disease groups it has been found out that the frequency of the cases and the days with acute infections of the upper respiratory tract (AIURT) have been brought under control. The frequency of occurrence of cases related to diseases of the peripheral nervous system and the eye tend to grow. With the continuous temporary incapacity for work we find out continuation when it comes to malignant growths, neuroses and cardiovascular diseases. The yearly occurrence of lost days because of accidents at the workplace decreases abruptly.

Conclusion: The indicators of the morbidity with temporary incapacity for work (MTIW) in 2004, 2005 and 2006 through comparing with norm groups after Batkis-Lekarev allow us to establish that the level of morbidity with temporary incapacity for work of the workers and administrative staff is very high.

The comparative analysis for the period 2004-2006 shows that the negative tendencies in the morbidity with temporary incapacity for work have decreased during the past year. The intensive indicators of frequency of the cases and frequency of the days away from work (MTIW) in 2006 are lower than they were during the previous year but they remain higher than the values for the first year that has been analysed. The relative share of the frequently sick people and those who were away from work for a long time after the increase during 2005 started to drop abruptly and towards the end of the period of research dropped below the initial level in 2004. The average length in days of one separate case with temporary incapacity for work tends to grow and this is a fact of serious concern.

A different tendency has been observed concerning the distribution of MTIW according to the sex criterion. The frequency of sickness cases with women in 2005 is considerably lower in relation to the previous period, but in 2006 it 
starts to grow again. Till the end of 2006 it remains at a low level unlike the high frequency of the lost work days. The few cases in combination with high incapacity for work with women indicate serious and complicated illnesses that led to temporary incapacity for work. On average each case of (MTIW) with women in 2006 has lasted for 13 days (13.20 days).

With men despite the slight decrease if the intensive indicators in 2006, they remain on the most unfavourable very high level. In 2004 the value of these indicators with men is at least two times higher than the indicators of women. In a work year of 252 days the absences from work with men in 2005 is $2,008.47$ days. The tendency of concern about increase of the duration of absences because of sickness remains the same with men and during the past year each patient's chart has lasted 11.81 days on average.

The structure of morbidity shows that the basic reasons for temporary incapacity for work of the working team as a whole are mainly diseases of the respiratory, musculo-skeletal system and diseases of the peripheral nervous system, which can be explained with the specific type of work. Special attention should be paid to the fact that the frequency of absences from work because of malignant growths grows double each following year. The progression of the sickness related to the peripheral nervous system, neuroses and eye diseases is similar. The presence of some of these diseases could be related directly with the working conditions.

\section{REFERENCES}

1. Melchior M, Berkman LF, Niedhammer I, Zins M, Goldberg M., The mental health effects of multiple work and family demands. A prospective study of psychiatric sickness absence in the French GAZEL study., Soc Psychiatry Psychiatr Epidemiol. 2007 Jul;42(7):573-82.

2. Halatek T, Sinczuk-Walczak H, Szymczak M, Rydzynski K., Neurological and respiratory symptoms in shipyard welders exposed to manganese., Int J Occup Med Environ Health. 2005;18(3):265-74

3. Sygit M, Weclawik Z., Problems of occupational rehabilitation in the shipbuilding industry. II. Rehabilitation in a group of ship welders, $\mathrm{Med} \mathrm{Pr}$. 1987;38(1):60-5

4. Liubchenko PN, Vinnitskaia TE., The structure of occupational morbidity in electric welders, $\mathrm{Med} \mathrm{Tr}$ Prom Ekol. 2000;(8):7-10.

5. Darnton AJ, McElvenny DM, Hodgson JT, Estimating the number of asbestos-related lung cancer deaths in Great Britain from 1980 to 2000., Ann Occup Hyg. 2006 Jan;50(1):29-38.

6. Greenberg M., Cancer mortality in merchant seamen., Ann N Y Acad Sci. 1991 Dec 31;643:321-32.

7. Selikoff IJ, Lilis R, Levin G., Asbestotic radiological abnormalities among United States merchant marine seamen., Br J Ind Med. 1990 May;47(5):292-7.

8. Jones RN, Diem JE, Ziskand MM, Rodriguez M, Weill H., Radiographic evidence of asbestos effects in American marine engineers., J Occup Med. 1984 Apr;26(4):281-4.

9. Danielsen TE, Lang rd S, Andersen A., Incidence of lung cancer among shipyard welders investigated for siderosis., Int J Occup Environ Health. 1998 Apr-Jun;4(2):85-8. 